\title{
Mente e comportamento
}

\author{
Mind and behavior
}

\section{João de Fernandes Teixeira}

Doutorado $(\mathrm{PhD})$ em Filosofia pela University of Essex, professor titular do Departamento de Filosofia da Universidade Federal de São Carlos (UFSCar), São Carlos, SP - Brasil, e-mail: jteixe@terra.com.br

\section{Resumo}

O artigo analisa a concepção de comportamento na psicologia. Duas concepções de comportamento são apresentadas, a primeira segundo o behaviorismo metodológico (Watson) e a segunda na concepção desenvolvida pelo behaviorismo radical (Skinner). Apontamos para a existência de uma grande diferença entre essas duas concepções. Apontamos também para uma nova possibilidade de compreensão da noção de comportamento no behaviorismo radical, segundo a qual comportamento é essencialmente interpretação. Essa ideia é desenvolvida num texto publicado por Skinner em 1988, na sua maturidade. Com isso buscamos lançar uma nova luz sobre o behaviorismo radical, no qual a noção de comportamento é distinta daquela presente na psicologia popular.

Palavras-chave: Comportamento. Skinner. Watson. Behaviorismo metodológico. Behaviorismo radical. 


\begin{abstract}
The paper focuses on the notion of behavior in psychology. Two conceptions of behaviorism, namely, methodological (Watson) and radical (Skinner) are focused and a major difference between them is detected. A new view of the notion of behavior in Skinner's behaviorism is brought to light in his mature text of 1988. According to such a view behavior is mainly interpretation and not observable physical/muscular motion. This is a new view to radical behaviorism, one that distinguishes it from our folk psychological conception of behavior, which is also the conception implicit in methodological behaviorism.
\end{abstract}

Keywords: Behavior. Skinner. Watson. Methodological behaviorism. Radical behaviorism.

Pode parecer estranho contribuir para uma edição especial desta revista, dedicada à filosofia da mente, com um artigo sobre a noção de comportamento e nele discutir teorias behavioristas. Falar de comportamento não está na moda. Esse tema pouco integra a pauta da filosofia da mente dos séculos XX e XXI. Poucas filosofias da mente, como é o caso da de Dennett ([1978] 1999), fazem alguma referência explícita ao comportamento. Mesmo assim, ele só aparece colateralmente na sua teoria dos sistemas intencionais, pois Dennett rejeita todos os tipos de behaviorismo.

A desaparição de uma reflexão sobre a natureza do comportamento se deve, em grande parte, à ascensão do cognitivismo, que, segundo alguns, se fez por contraposição aos behaviorismos, já exaustos a partir dos anos 1960. Não fosse pelo aparecimento da neurociência cognitiva na década do cérebro, esse tópico permaneceria banido da agenda da filosofia da mente até hoje.

$\mathrm{O}$ que distingue o comportamento de um termostato do comportamento de um ser humano? O conceito de comportamento é um dos problemas mais difíceis da filosofia da psicologia e, ao mesmo tempo, algo que se apresenta como extremamente intuitivo e trivial. A ideia cotidiana derivada da psicologia popular (folk psychology) e também adotada por alguns behavioristas metodológicos é que o comportamento pode ser identificado com movimento muscular observável. 
Certamente, não é esse o conceito de comportamento que encontramos na obra de Skinner. Ele rompe com a visão filosoficamente ingênua que o concebe como movimento muscular observável e que era típica do behaviorismo metodológico, ou seja, do behaviorismo de Watson.

Da perspectiva de Watson, o comportamento observável deveria ser o ponto de partida e o caminho privilegiado para o estudo da mente. Watson define o comportamento em termos de estímulos e respostas; as leis para a regulação do comportamento são as leis de "ajustamento", que ele conceitualizou como relações entre respostas e estímulos. Uma resposta abrange atos definidos em termos de categorias de ação (por exemplo: conversar, nadar) ou de ação dirigida a um fim, como ocorre quando se escreve uma carta. O mental não é observável, nem tampouco detectável, e, por isso, ele não poderia participar da ciência, a não ser indiretamente. A solução dada por Watson para esse problema foi excluir o mental do discurso da psicologia e, junto com ele, todo vocabulário mentalista, ou seja, toda referência a estados subjetivos. No seu texto ele afirma:

A Psicologia, tal como o behaviorista a vê, é um ramo puramente objetivo e experimental da ciência natural. A sua finalidade teórica é a previsão e o controle do comportamento. A introspecção não constitui parte essencial dos seus métodos e o valor científico dos seus dados não depende do fato de se prestarem a uma fácil interpretação em termos de consciência (WATSON, 1913a, p. 158).

É preciso notar que, com tais declarações, o behaviorismo metodológico acaba, paradoxalmente, abraçando uma visão cartesiana. A exclusão do mental separa radicalmente mente e corpo tanto quanto Descartes o fez. O mental não pode ser objeto de ciência. À psicologia só restaria falar do corpo, por ser ele a entidade observável que se movimenta.

No seu manifesto, Watson (1913a) afirma que o comportamento humano possui, essencialmente, as mesmas características do comportamento de outros animais. Consequentemente, ambos poderiam ser estudados utilizando os mesmos métodos de investigação. No entanto, o autor faz uma ressalva, ao reconhecer o importante papel da linguagem no estudo da percepção, e admite que os métodos por ele propostos poderiam ser insuficientes ao estudo de "formas mais complexas do comportamento, como a imaginação [...]" (WATSON, 1913b, p. 173). De qualquer forma, continuou sustentando a afirmação de que os processos responsáveis pelos hábitos explícitos são também 
responsáveis pelos hábitos internos. Dessa forma, todo comportamento poderia ser descrito em termos de reflexo, ou seja, em termos de ação sensóriomotora. Assim, o pensamento efetivo, por exemplo, poderia ser visto como a adaptação de respostas privadas da laringe à demanda crescente da estimulação ambiental.

Contudo, as concepções do behaviorismo metodológico revelaramse insuficientes para explicar comportamentos complexos como os dos seres humanos. Nem todos os comportamentos podiam ser descritos como resultando de uma trajetória direta entre estímulo e resposta, como queria Watson. Havia comportamentos que não eram produzidos por estímulos observáveis. E havia também os comportamentos improvisados, cuja explicação também constituía um grande problema para esse tipo de behaviorismo.

As críticas mais contundentes ao behaviorismo metodológico vieram da filosofia. Foi Gilbert Ryle quem desfechou o ataque mais notável ao behaviorismo em geral. Ele não distinguia entre behaviorismo metodológico e radical, tomando-os como um bloco monolítico. Embora tenha sido contemporâneo de Skinner e um filósofo da mente notável para sua época, não parece ter havido contato entre os dois. Em sua obra The Concept of Mind, publicada em 1949, Skinner é mencionado apenas uma vez.

Ryle afirmava que, por critérios behavioristas, não podemos distinguir quando um palhaço cai por acaso ou de propósito. No ensaio The thinking of thoughts: what is 'le penseur' doing? ([1968] 2009) ele descreve uma situação peculiar. Ryle considera a situação hipotética de dois garotos numa reunião de condomínio. Ambos piscam simultânea e rapidamente um de seus olhos. Em um deles, esse é um tique involuntário, no outro é uma piscadela conspiratória para um amigo. Ora, vendo essa cena por meio de uma câmera, ou seja, a partir de uma observação fenomenalista, não poderíamos saber qual deles estava piscando por motivos conspiratórios e qual por conta de um tique nervoso. especial:

O piscador voluntário está se comunicando de uma forma precisa e

a) deliberadamente;

b) para alguém em particular;

c) transmitindo uma mensagem específica;

d) de acordo com um código socialmente estabelecido;

e) sem o conhecimento dos demais companheiros. 
Segundo Ryle, o piscador voluntário executa duas ações, contrair a pálpebra e piscar, enquanto o que tem tique nervoso executou apenas uma, ou seja, contraiu a pálpebra. A diferença entre um tique nervoso e uma piscadela é grande. Poderia, ainda, ser o caso de que o piscador voluntário, que pisca para o outro em atitude conspiratória, esteja fazendo isso apenas para imitar a existência de uma possível conspiração. Também poderia haver um terceiro tipo de ação: a de alguém que imitasse a ação dos outros dois apenas para ridicularizá-los.

Como o behaviorista, ou seja, alguém na posição de estar apenas assistindo um filme do que aconteceu, poderia saber se há duas ou até três ações numa piscadela? Essa era a pergunta de Ryle.

Na verdade, o que Ryle perguntava, com o relato dessa situação, era se o comportamento, para existir, não dependeria da existência de uma interpretação. Só interpretando podemos distinguir se uma piscadela é involuntária, conspiratória ou apenas uma imitação de conspiração feita apenas para debochar dos participantes da reunião. Certamente, essa é uma boa objeção ao behaviorismo metodológico. Ou seja, não podemos conceber o comportamento apenas a partir da percepção do movimento muscular.

Em sua concepção de comportamento, o behaviorismo metodológico sucumbe à do senso comum. Ryle mostra o quanto ela é insuficiente. Para distinguir uma piscadela involuntária de uma conspiratória é preciso descrever o comportamento usando uma linguagem mentalista. Uma conspiração exige a atribuição de crenças e intenções a alguém; sem isso, não existe atitude conspiratória e nem podemos descrevê-la.

Ao admitirmos a necessidade da descrição intencional - seja com "c" ou com "s" -, parece que chegamos ao limite de qualquer abordagem psicológica que reduza o mental ao comportamento. $\mathrm{O}$ mentalismo sempre entra pela porta dos fundos. Pior do que isso: mesmo que se mostre que esses eventos privados são materiais - como é o caso de Fodor, que diz poder conciliar o mentalismo com o materialismo -, ainda assim eles são essencialmente eventos internos privados que desafiam qualquer descrição periferalista do comportamento. Fica difícil sustentar o behaviorismo metodológico.

Mas, e quanto ao behaviorismo radical de Skinner, será que ele sucumbe à crítica de Ryle? Para Skinner, à diferença de Watson, estados mentais existem, embora sejam causalmente inoperantes. A situação não parece mudar muito, mas vale a pena começarmos por nos interrogar acerca da concepção de comportamento do behaviorismo radical de Skinner. 
Em 1937, Skinner criou a ideia de comportamento operante e, com isso, inaugurou o behaviorismo radical. No comportamento operante, o estímulo pode ser inobservável. E nele as consequências do comportamento podem retroagir sobre o organismo. Ao contrário do que acontece no comportamento reflexo ou no comportamento respondente (como é o analisado por Watson), no comportamento operante há variáveis que tornam mais provável sua ocorrência e não simplesmente estabelecem uma relação direta de causa e efeito.

Primeiramente, há o tipo de resposta que é eliciada por uma estimulação específica, em que a correlação entre a resposta e o estímulo é um reflexo no sentido tradicional. Irei classificar esse reflexo de respondente. [...] Mas há também um tipo de resposta que ocorre espontaneamente na ausência de qualquer estimulação com a qual ela possa estar especificamente correlacionada. [...] É da natureza desse tipo de comportamento ocorrer sem um estímulo eliciador, embora estímulos discriminativos sejam praticamente inevitáveis após o condicionamento. Não é necessário identificar unidades específicas antes do condicionamento, mas durante o condicionamento elas poderão se estabelecer. Irei chamar tais unidades de operantes, e o comportamento em geral de comportamento operante (SKINNER, 1961c, p. 378).

É nesse texto que pela primeira vez Skinner utilizou o termo "operante" (SKINNER, 1980/1998). O operante exigiria outra estratégia, já que não haveria relações respondentes previamente identificáveis ou estímulos eliciadores específicos (SKINNER, 1937/1961a). Na definição do reflexo, a única propriedade que devemos considerar é a própria relação, isto é, a coincidência da ocorrência de um estímulo seguida da ocorrência de uma resposta.

A resposta operante é essencialmente uma ação do organismo que produz efeitos no ambiente. As consequências, por sua vez, são as modificações geradas pela resposta do organismo. Para Skinner, o organismo sempre está inserido em um ambiente. No caso do respondente, os estímulos eliciadores são eventos ambientais responsáveis diretamente pela ocorrência da resposta reflexa. Já no operante, o ambiente é constituído por estímulos discriminativos.

A diferença essencial é que, ao invés de eliciarem a resposta, os estímulos discriminativos constituem a ocasião em que uma dada resposta operante será seguida da consequência reforçadora (SKINNER, [1945] 1961c, [1953] 1965, 1966c, 1967, 1975). É importante ressaltar que, embora não atue 
diretamente como causa da resposta, tal como ocorre no respondente, o estímulo discriminativo é também responsável pelo controle do comportamento no âmbito operante (SKINNER, [1953] 1965, 1966c, 1989). Avalia-se o grau de controle do estímulo discriminativo de acordo com as variações na frequência de respostas, o que nos possibilita inferir a probabilidade de que uma resposta possa ocorrer numa dada ocasião (SKINNER, 1969).

A ocorrência de uma resposta nunca é idêntica à ocorrência de outra. É por isso que no behaviorismo radical fala-se de "classes de respostas" e "classes de estímulos" e é justamente por isso, também, que Skinner ([1935] 1961a, [1938] 1966b, 1979, [1980] 1998) afirma que os estímulos e as respostas são conceitos de natureza genérica, passíveis de identificação apenas por meio das relações funcionais estabelecidas entre os eventos estudados.

Contudo, se uma resposta nunca é idêntica à outra, como uma consequência poderia surtir qualquer efeito na resposta que já ocorreu? Ou seja, como seria possível o processo de condicionamento? De acordo com Skinner ([1953] 1965, 1989), as consequências não alteram as respostas que já ocorreram, mas sim a probabilidade de que respostas que pertencem à mesma classe possam ocorrer no futuro. É nesse contexto que o termo "reforço" faz sentido. Dizemos que um evento é reforçador quando ele fortalece a classe operante da qual faz parte no sentido de aumentar a probabilidade de que respostas que pertençam à mesma classe ocorram (SKINNER, [1953] 1965, 1974).

Com essas novas ideias acerca do comportamento, Skinner teria dado um grande passo para além da psicologia estímulo-resposta, comumente vista como mecanicista. $\mathrm{O}$ modelo de comportamento inspirado no operante tem raízes adaptativas, darwinianas, por contraposição ao proposto inicialmente por Watson (e antes dele, por Pavlov). No behaviorismo radical o dado experimental básico é a frequência das respostas que, por sua vez, são funcionalmente classificadas dentro de uma mesma classe, de acordo com as consequências reforçadoras que as seguem. Diferentemente do modelo watsoniano e pavloviano, não é preciso sustentar também uma relação do tipo "tudo ou nada", já que estamos lidando com probabilidades de ocorrência de respostas pertencentes a uma classe.

Mas o que é comportamento para o behaviorismo radical? Até que ponto as idéias de Skinner podem nos ajudar a superar os problemas levantados por Ryle?

Sem dúvida, Skinner rompe com a tradição de Watson e também com uma percepção intuitiva do comportamento, que o identifica com o movimento muscular observável. A ideia de probabilidade introduz um termo 
teórico na percepção do comportamento. A percepção do movimento muscular passa a ser teórico-carregada (theory-laden). Ou, em outras palavras, há muito mais no comportamento do que aquilo que simplesmente nos é dado pela sua percepção.

Ecos de que Skinner reconhece a persistência do problema levantado por Ryle é o seu reconhecimento, num texto de maturidade, que o comportamento é interpretação. ${ }^{1}$ Em 1988, Skinner, em uma de suas respostas a várias objeções levantadas por ocasião de um simpósio na revista Brain and Behavioral Science, nos diz que:

Não existe uma essência do comportamento. A própria expressão "o que o organismo faz" é problemática, pois ela implica que o organismo inicie seu comportamento. [...] Não penso que comportamento seja, necessariamente, ação muscular. Nós o observamos seja através da introspecção [...] ou através de medidas fisiológicas que "invadem a privacidade". Na falta de dados melhores, uma ciência do comportamento só pode oferecer uma interpretação (SKINNER, 1988, p. 469).

Com isso Skinner rejeita explicitamente a associação entre comportamento e movimento muscular perceptível. Skinner nunca abraçou a concepção de comportamento herdada pelo senso comum e compartilhada com o behaviorismo metodológico. Não se pode confundir behaviorismo radical com behaviorismo metodológico. Mas por que a concepção de comportamento de Skinner é frequentemente confundida com a do behaviorismo metodológico?

A confusão vem do viés neopositivista com que a obra de Skinner é frequentemente interpretada. O neopositivismo defendia que a psicologia devia ter uma linguagem estritamente fisicalista - ou seja, dela devia ser extirpado todo vocabulário psicológico, pois não é possível retraçar sua origem no mundo sensível.

Ao introduzir a ideia de comportamento como interpretação, Skinner se situa fora da tradição empirista e do neopositivismo também. Pois se trata de afirmar que a observação do comportamento é mais do que teórico-carregada. Não há observação do comportamento que não seja simultaneamente interpretação. Creio que isso pode mudar a compreensão do behaviorismo radical que tivemos até hoje.

1 Agradeço a Diego Zílio por ter me chamado a atenção para o trecho de Skinner que segue.

Rev. Filos., Aurora, Curitiba, v. 22, n. 30, p. 27-40, jan./jun. 2010 
Uma das consequências desse trecho de Skinner, escrito em 1988, é que ele reconhecia - ou pelo menos reconheceu na sua maturidade - que o sonho de uma ciência psicológica que pudesse preencher o ideal das ciências naturais não seria possível. $\mathrm{O}$ ideal de precisão de uma ciência inteiramente escrita em linguagem extensional tem de ser abandonado. A psicologia tem de ser uma ciência soft. Não importa, tampouco, que estejamos falando de comportamento como fenômeno biológico. A biologia também é uma ciência soft, pois não é inteiramente escrita em vocabulário extensional.

Podemos ver como, a partir desse trecho, a articulação teórica do behaviorismo radical torna-se mais clara. Por exemplo, ao tratar o comportamento como algo teórico-carregado (probabilidade) e como interpretação, Skinner pôde ampliar o behaviorismo, estendendo-o para a compreensão dos fenômenos mentais também. Falar de interpretação abre a porta para a introdução do inobservável no discurso da psicologia. Isso permitiu que, em vez de pura e simplesmente desprezar o vocabulário mentalista e tentar varrê-lo para debaixo do tapete, o mental passasse a ser considerado como um tipo de comportamento. Pensar, calcular e raciocinar são, na visão skinneriana, comportamentos encobertos. O comportamento encoberto é uma interpretação da atividade cerebral como uma classe de comportamentos que não são diretamente observáveis.

Para o behaviorismo radical, a mente é uma coleção de comportamentos encobertos. O behaviorismo de Skinner torna-se radical quando engloba também o psiquismo, entendido nessa acepção. Na verdade, o que Skinner faz é reincluir a mente na psicologia, apesar de considerar a consciência como inteiramente constituída pela linguagem - a linguagem que ele quer estudar na forma de comportamento lingüístico.

Se há críticas ao behaviorismo skinneriano, elas não devem recair no estereótipo de que ele seria uma "psicologia sem mente". O pensamento é um comportamento não observável. Anima vem de "animado", ou o que se movimenta, tanto visível como invisivelmente. Pensar é movimentar-se, da mesma maneira que nossos músculos se movimentam e formam nossa concepção de comportamento derivada do senso comum, ou seja, sua visão apenas como macrofenômeno observável.

A ideia de comportamento encoberto como fenômeno invisível também rompe com o mito neopositivista de que só se pode falar daquilo que, em última análise, é rastreável na experiência sensível ou em algo observável. Skinner não segue essa tradição neopositivista - como muitos pensam - só porque foi contemporâneo dela. Mas também não endossa a oposta, o 
dualismo, ou a ideia de que mente/corpo deveriam ser separados, e de que o mental seria uma entidade inescrutável por não ser acessível à observação.

Ao admitir que o comportamento é, sempre, uma leitura possível do movimento, seja esta atividade do psiquismo (comportamentos encobertos), seja uma atividade que se traduz em movimento muscular, Skinner reconhece a dificuldade levantada pela crítica de Ryle. O comportamento, mesmo como atividade unicamente muscular, está impregnado de crenças, intenções, desejos, etc. Ora, seriam essas entidades inevitáveis na descrição do comportamento? Haverá, na descrição do comportamento, resíduos mentalistas inelimináveis?

São esses resíduos inelimináveis que nos permitem identificar e, ao mesmo tempo, depurar os usos abusivos da noção de comportamento quando falamos do "comportamento de um termostato" ou "comportamento de um carro na pista de corrida". Esses "comportamentos" não poderiam ser descritos a partir de intenções e crenças, a não ser que façamos um esforço linguístico visivelmente inapropriado. Isso quer dizer que toda descrição do comportamento humano tem que incluir algum termo mentalista. $\mathrm{O}$ termo mentalista é a interpretação de que nos fala Skinner. É ele que distingue nosso comportamento do comportamento de um termostato, e também do comportamento concebível unicamente como movimento muscular observável.

Chegamos então a algo parecido com uma definição: comportamento é uma descrição mentalista do movimento. Uma descrição que pode ser estendida também ao funcionamento cerebral. Isso é algo bem diferente do que pensa o senso comum e também o neopositivista.

Crenças, intenções e desejos podem também ser vistas como entidades teóricas que projetamos sobre o movimento muscular para torná-lo inteligível. Se despirmos o comportamento dessas entidades teóricas - como Watson gostaria de ter feito -, despimo-lo também de sentido. Sentido não pode ser mapeado no mundo físico. Comportamento é um modo de descrição do movimento - o modo que interessa à psicologia. À fisiologia, por exemplo, interessará outro recorte. A fisiologia das pernas dos jogadores de futebol não explica como se joga esse tipo de jogo. As descrições do fisiologista e do jogador de futebol não são incompatíveis, embora tenham focos ou pontos de partida diferentes e definam níveis de descrição também diferentes. Da mesma maneira, o que interessa à psicologia é um tipo específico de descrição do movimento, que não inclui sua decomposição em propriedades biológicas.

O limite da psicologia experimental é a descrição puramente fisicalista do comportamento. A psicologia não pode se furtar da elaboração teórica, mesmo quando feita unicamente em laboratório. Isso não significa diminuir a 
importância dos experimentos, mas, apenas, enfatizar igualmente a relevância das análises funcionais. Será a partir desta que se definirão os experimentos cruciais a serem realizados no laboratório. Infelizmente, parece que os skinnerianos têm dado maior preponderância aos aspectos empíricos do comportamento, como se as análises funcionais pudessem ser ignoradas. Em outras palavras, os skinnerianos continuam neopositivistas, embora Skinner nunca o tenha sido.

Esquecer os aspectos funcionais e interpretativos do comportamento tem levado a paradoxos como, por exemplo, montar modelos behavioristas para o comportamento sadomasoquista. Não se pode pretender que tais modelos imitem esse tipo de comportamento, pois, no máximo, consegue-se imitar os movimentos musculares que o compõem. Tampouco poderíamos dizer que um animal treinado para guardar notas de Real em seu ninho tenha aprendido o valor do dinheiro. Faz-se, aqui, um mesmo tipo de transgressão categorial inversa à que ocorre na nossa linguagem cotidiana ao falarmos de comportamento do termostato ou de um robô. Ou seja, atribui-se à descrição fisicalista do comportamento mais do que ela pode conter.

Sabemos que um dos grandes méritos de Skinner foi livrar-se das concepções mecanicistas de comportamento, de acordo com as quais estímulo e comportamento seriam separáveis do mesmo modo que causa e efeito. $\mathrm{O}$ modelo do comportamento reflexo é mecânico: o estímulo $\mathrm{S}$ elicia a resposta R. Mas no operante proposto por Skinner, o modelo é biológico, pois há uma seleção natural do comportamento mais adequado na sua interação e retroação com o meio ambiente.

A adaptabilidade - conceito subjacente ao de comportamento operante - é também uma entidade não observável e intensional. Características que dão adaptabilidade a um organismo num ambiente podem não ser adaptativas em outro. Isto quer dizer que não existe nada intrinsecamente adaptável e que ao falarmos de adaptabilidade não estamos nos referindo nunca a um conjunto de propriedades enumeráveis que encontraríamos em todos os organismos que pertencem a um determinado meio ambiente. A adaptabilidade também é uma interpretação, tanto quanto a teoria da evolução, que é um modo de contar a história da natureza. E talvez o mesmo possamos dizer do operante, que, embora definido apenas em termos biológicos, talvez não possa prescindir das noções mentalistas de agradável/desagradável para o organismo.

A maioria dos behavioristas radicais leu mal a obra de Skinner. Assumiu, implicitamente, uma concepção de comportamento derivada da psicologia popular e que foi reforçada pela interpretação neopositivista. O pano 
de fundo foi a proposta da possibilidade da psicologia adotar um discurso exclusivamente fisicalista, como foi defendido por Carnap. Mas Skinner não era nem neopositivista nem antimentalista. Seu antimentalismo restringe-se ao anticartesianismo. A mente não pode ser algo imaterial, que misteriosamente interage com o corpo. Ele concordaria com Fodor, no sentido de que não existe incompatibilidade entre mentalismo e materialismo. A mente é a interpretação de um comportamento encoberto, qual seja, o metabolismo do cérebro.

Quem ainda faz uma interpretação neopositivista de Skinner - o que é ainda muito comum - presta um desserviço à história das ideias psicológicas. Afinal, comportar-se não é só mexer-se; falar de comportamento envolve também uma percepção específica daquilo que se mexe. Não podemos traçar uma distinção inteiramente nítida entre observação e interpretação. Skinner concordaria com isso e, ao fazê-lo, rompe com a tradição neopositivista. Nesse sentido, poderíamos afirmar, com ele, que nem tudo que se mexe se comporta, e nem tudo o que se comporta se mexe.

O que foi exposto não deve ser interpretado como uma defesa dos méritos de Skinner. Trata-se tão somente de evitar interpretações errôneas do conceito de comportamento, que pode ter efeitos deletérios sobre o behaviorismo radical. É preciso enfatizar que Skinner é materialista, mas não reducionista. No behaviorismo radical não se busca uma redução de termos intencionais a comportamento observável. Esse é um programa neopositivista cujas raízes provavelmente estão no behaviorismo metodológico e na concepção de comportamento que nos é dada pela psicologia popular.

O behaviorismo metodológico parece estar sendo reavivado pela neurociência cognitiva. Não nos cabe aqui, por falta de espaço, discutir um tema tão amplo como as relações entre behaviorismo e neurociência cognitiva. Cabe, entretanto, assinalar que as modernas técnicas de neuroimagem baseiamse num esquema $\mathrm{S}-\mathrm{R}$, no qual os estímulos são procurados dentro do cérebro.

A caixa preta cerebral tende a ser aberta. Skinner menciona isso no texto de 1998 que reproduzimos acima. Mas o programa reducionista explícito de muitos neurocientistas cognitivos não ameaça uma ciência do comportamento. Esse programa reducionista ainda não dá conta das retroações do comportamento que dependem do meio ambiente para se realizarem. Ou seja, a neurociência cognitiva pode deixar de dar conta das consequências do comportamento. O cérebro não pode representar completamente o ambiente onde ele mesmo se encontra.

Tampouco o neurocientista deixa de interpretar os comportamentos antes de relacioná-los com a ativação de algumas áreas cerebrais. O sujeito 
da neuroimagem também interpreta o que supostamente está ocorrendo no seu cérebro. Só então pode ser estabelecida uma relação entre área cerebral ativada e comportamento.

O caráter intensional de comportamento faz com que ele só se constitua se estiver conectado a objetos fora do cérebro. Ou, em outras palavras, a ciência do comportamento não é redutível a uma ciência do cérebro, tal como ela é concebida pelos neurocientistas cognitivos. Mas esse é, certamente, tema para outro artigo.

\section{Referências}

DENNETT, D. Sistemas intencionais. In: Brainstorms. São Paulo: UNESP, 1999. p. 33-55. Texto originalmente escrito em 1978.

RYLE, G. The concept of mind. New York: Barnes and Noble, 1949.

. The thinking of thoughts: what is 'le penseur' doing? In: RYLE, G. Collected essays 1929-1968. London: Routledge 2009. v. 2. p. 480-486. Artigo publicado originalmente em 1968.

SKINNER, B. F. The generic nature of the concepts of stimulus and response. In: Cummulative record: a selection of papers. 2nd ed. New York: Appleton-Century-Crofts, 1961a. p. 347-366. Obra original publicada em 1935.

. The operational analysis of psychological terms. In: SKINNER, B. F. Cummulative record: a selection of papers. 2nd ed. New York: Appleton-CenturyCrofts, 1961b. p. 272-286. Obra original publicada em 1945.

. Two types of conditioned reflex: a reply to Konorski and Miller. In: SKINNER, B. F. Cummulative record: a selection of papers. 2nd ed. New York: Appleton-Century-Crofts, 1961c. p. 376-383. Obra original publicada em 1937.

Science and human behavior. New York: The Free Press, 1965. Obra original publicada em 1953.

. The phylogeny and ontogeny of behavior. Science, New Series, v. 153, n. 3741 , p. $1205-1213,1966 a$.

The behavior of organisms: an experimental analysis. New York: AppletonCentury-Crofs, 1966b. Obra original publicada em 1938. 
The problem of consciousness: a debate. Philosophy and Phenomenological Research, v. 27, n. 3, p. 325-337, 1967.

- Contingencies of reinforcement: a theoretical analysis. New York: Appleton-Century-Crofts, 1969.

. About behaviorism. New York: Alfred A. Knopf, 1974.

. The steep and thorny way to a science of behavior. American Psychologist, v. 30, n. 1, p. 42-49, 1975.

. The shaping of a behaviorist: part two of an autobiography. New York: Alfred A. Knopf, 1979.

. The listener: recent issues in the analysis of behavior. Ohio: Merrill Publishing Company, 1989. p. 35-47.

. The experimental analysis of operant behavior: a history. In: RIEBER, R. W.; SALZINGER, K. D. (Ed.). Psychology: theoretical-historical perspectives. 2nd ed. Washington: American Psychological Association, 1998. p. 289-298. Obra original publicada em 1980.

WATSON, J. B. Psychology as the behaviorist views it. Psychological Review, v. 20, p. 158-77, 1913a.

. Image and affection in behavior. Journal of Philosophy \& Psychology, v. 10, p. 421-428, 1913b.

Recebido: $23 / 04 / 2010$

Received: 04/23/2010

Aprovado: $12 / 05 / 2010$

Approved: 05/12/2010 